\title{
Performance analysis of the process of combine harvesting of grain crops
}

\author{
Victor Kataev ${ }^{1}$, Ilia Markvo ${ }^{1, *}$, Kaprel Khubiian ${ }^{1}$, and Valery Dimitrov ${ }^{1}$ \\ ${ }^{1}$ Don State Technical University, 1, pl. Gagarina, 344002, Rostov-on-Don, Russia
}

\begin{abstract}
The effectiveness of combine harvesting processes is one of the most important indicators of planting enterprises, as it largely determines the efficiency of the entire organization. One of the problems in assessing the effectiveness of combine harvesters is the determination of the planned performance of machines with rated productivity. The paper considers approaches to determining the planned and actual performance of the processes of combine harvesting of grain crops. The factors affecting the decrease in the performance of combines have been studied. The analysis of data on the wheat harvesting process in local organizations of the South of Russia during 2014-2019 has been carried out. The results of calculating the planned and actual performance of wheat harvesting processes in these farms are presented.
\end{abstract}

\section{Introduction}

Combine harvesters $(\mathrm{CH})$ are one of the most complex and expensive means of mechanization in crop production. Moreover, the result of the annual production cycle is largely determined by the quality of the harvesting process (in particular, grain crops). The main work in the process of harvesting of grain crops is performed using a combine harvester and means of transporting the crop to storage sites. The purchase and maintenance of combine harvesters suggests significant costs and the maximum use of each unit of equipment becomes very important for agricultural producers. On the one hand, the harvesting time from the stage of the full maturity of the grain until the end of harvesting leads to an increase in biological losses of the crop. On the other hand, incomplete loading of equipment leads to unnecessary (sometimes excessive) costs for the purchase, maintenance, salaries, etc. To assess the state of the processes of combine harvesting of grain crops, it is necessary to determine the indicators of their performance and effectiveness.

Existing approaches to assessing the performance and effectiveness of combine harvesters usage consider only some aspects of the harvesting processes and do not provide grounds for determining the potential of agricultural producers. For instance, the effectiveness of the work is estimated by the actual threshing or actually harvested area per machine during the harvesting period, the duration of harvesting. Such estimates do not

\footnotetext{
*Corresponding author: iluhan_markvo@mail.ru
} 
allow to evaluate how this corresponds to the real equipment capabilities claimed by the manufacturer.

If the performance of the process of mechanized harvesting of grain crops is defined as the ratio of planned and actually achieved results, the productivity indicator is always close to 100 percent (it is very rare that not all sown areas are harvested with a satisfactory yield). Moreover, the quality of the process is estimated only by the amount of costs (grain loss, fuel consumption, purchase of spare parts, depreciation, wages, etc.) associated with its implementation.

Such an approach to assessing the processes of mechanized harvesting of grain crops makes it difficult to find ways to increase the performance and efficiency of this process, therefore, alternative options for evaluating the performance should be considered.

\section{Research status and work relevance}

To assess the processes in management systems, two groups of indicators have been taken into consideration - effectiveness indicators and performance indicators:

- effectiveness is the ratio between the achieved result and used resources;

- performance is the degree of implementation of the planned activity and achievement of the planned results.

The presented definitions show that the evaluation of the effectiveness is directly related to the assessment of the performance, since both of these indicators require determining the actually achieved result, however, to determine the effectiveness it should be attributed to the expenses on achieving this result, and to determine the performance - to the planned results.

Effectiveness and performance indicators can be described by the following formulas, (1) and (2) respectively.

$$
E I=\frac{\mathrm{P}_{a}}{\sum E_{r}}
$$

where: $P_{a}-$ an indicator (assessment) of the actually achieved results;

$\sum E_{r}$ - assessment of the total expenses on achieving the results.

$$
P I=\frac{\mathrm{P}_{a}}{\mathrm{P}_{p}}
$$

where: $P_{a}-$ an indicator (estimation) of the actually achieved results; $P_{p}$ - planned results.

At evaluating complex systems, the calculation of effectiveness and performance indicators, of course, cannot be reduced to such a simple formula, since both the dividend and the divisor in formulas (1) and (2) are themselves complex integrated estimates.

At evaluating the effectiveness of using the combine harvester fleet, the assessment of the achieved results is natural, reflecting the purpose of the combine harvesting process. The actual performance estimates this. The performance of combine harvesters is usually expressed through the capacity $(\mathrm{kg} / \mathrm{s})$, the productivity of the main product (tons/h;), or the harvested area $(\mathrm{ha} / \mathrm{h})$. These indicators are correlated and can be expressed through each other.

Considering the fact that the main load during combine harvesting of grain crops falls on the threshing and separating device (thresher), the productivity of the combine harvester is limited by its capacity. The threshing capacity means the maximum amount of grain mass that the combine can process per unit of time in compliance with agrotechnical requirements.

Then the correlation between the capacity of the harvester and the size of the harvested 
area can be described by the following dependence:

$$
S=\frac{q}{Y(1+K r+K s)} \times t_{h}
$$

where: $\mathrm{S}-$ the area harvested by the combine harvester, ha;

$q$ - the capacity of the combine harvester, $\mathrm{kg} / \mathrm{s}$;

$\mathrm{Y}$ - the yield capacity, $\mathrm{kg} / \mathrm{ha}$;

$\mathrm{K}_{\mathrm{r}}$ - the ratio of straw and grain by weight (standard value of 1.5:1);

$\mathrm{K}_{\mathrm{s}}$ - crop stand by weight, $\%$;

$\mathrm{t}_{\mathrm{h}}$ - operating time, sec.

The planned performance should be determined on the basis of the need to fully load the combine harvester, that is, as the multiplication of the combine harvester productivity and the calendar time of the harvesting duration. To determine the planned (ideal) performance, it is necessary to equate the harvesting time $\left(t_{h}\right)$ in expression (3) with the calendar time from the beginning to the end of harvesting:

$$
\mathrm{P}_{a}=S_{a}=\frac{q}{Y(1+K r+K s)} \times t_{h c}
$$

where: $\mathrm{P}_{a}, S_{a}$ - the planned performance expressed in terms of the planned number of the harvested areas;

$t_{h c}$ - is the planned harvesting time corresponding to the calendar time from the beginning to the end of harvesting.

The planned value of the performance of the combine harvesting processes cannot be achieved due to the influence of a number of reasons, among which the main ones are [1-3]:

- reduced performance due to technical condition;

- reduced performance due to technological adjustment;

- reduced performance for organizational reasons;

- decrease in performance due to weather (climatic) conditions.

The influence of the above mentioned reasons on the actual performance of the harvesting processes is presented in Figure 1.

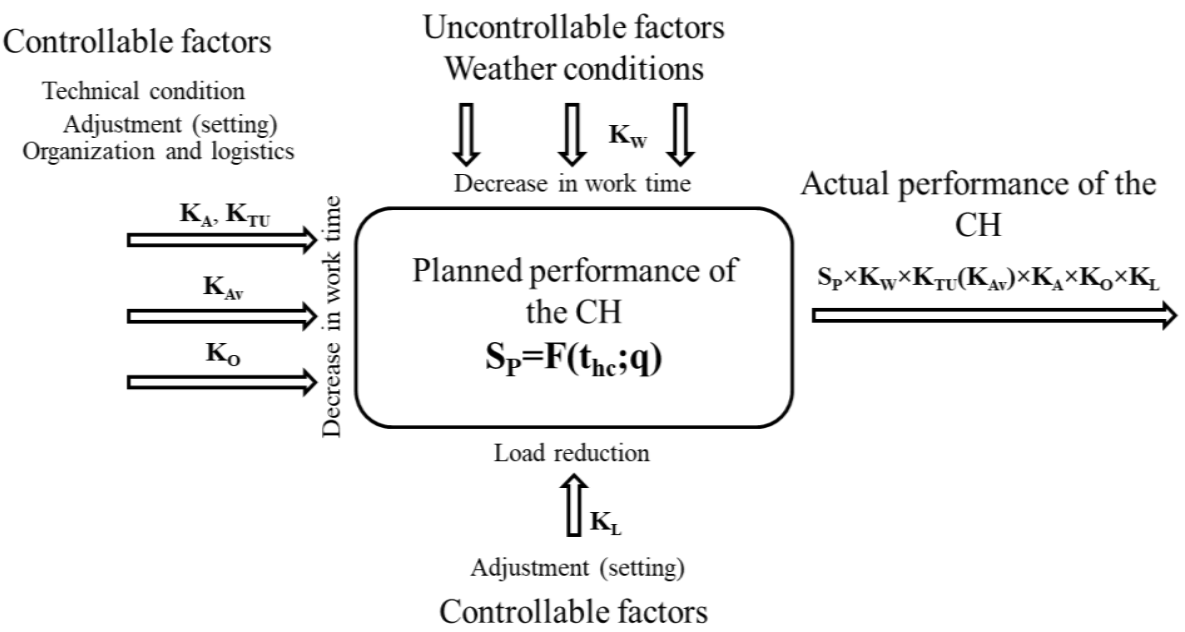

$K_{A v}$ - availability factor; $K_{t u}$ - coefficient of technical use; $K_{A}-$ coefficient of technological adjustment (setting); $K_{D}$ - coefficient of organizational downtime; $K_{L}-$ load factor of the $\mathrm{CH} ; K_{W}-$ coefficient of weather conditions; $S_{P}$ - planned harvested area; $t_{h c}$ - planned harvesting time; $q-$ the productivity of the combine harvester.

Fig. 1. Factors affecting the actual performance of the combine harvester. 
Weather (climatic) conditions significantly affect the efficiency of the combine harvesting processes. Precipitation and daily fluctuations in air humidity lead to the fact that it is impossible to harvest crops daily and around the clock.

It is reasonable to correct the planned value of the performance of the combine harvesting processes by the value of the coefficient of weather conditions, reflecting a decrease in the available harvesting time due to weather (climatic) conditions:

$$
\mathrm{P}_{\Pi}=S_{\Pi}=\frac{q}{Y\left(1+\mathrm{K}_{r}+\mathrm{K}_{c}\right)} \times t_{h c} \times K_{W},
$$

where: $K_{W}$ - weather coefficient:

$$
\mathrm{K}_{W}=\frac{t_{g w}}{t_{g w}+t_{b w}}
$$

where: $t_{g w}$ - the average time during which weather and climatic conditions did not impede the implementation of mechanized harvesting;

$t_{b w}-$ is the average time during which weather and climatic conditions did not allow mechanized harvesting.

Among the technical reasons for reducing the performance of technological processes of combine harvesting, it is possible to single out the indicators related to the aspects of managing the technical condition of combine harvesters - repair and maintenance of machines [4-6]. Maintenance is an integral part of the operation system of machines, without which it is impossible to ensure their proper functioning throughout the service life of the machine.

Implementation of a set of maintenance activities reduces the operating time of combine harvesters, thereby reducing the total threshing and harvested area, that is, the actual performance of the grain harvesting process [7].

The decrease in performance associated with the technical condition of the machines should be evaluated using the availability factor or the technical utilization rate of the equipment. These concepts are defined in [8-10].

Availability factor is the probability that the object will be in working order at a given time:

$$
K_{a}=\frac{\overline{\mathrm{T}}_{f}}{\overline{\mathrm{T}}_{f}+\overline{\mathrm{T}}_{r}}
$$

where: $K_{a}$ - availability factor;

$\overline{\mathrm{T}}_{f}$ - average failure interval;

$\overline{\mathrm{T}}_{r}$ - average recovery time.

The coefficient of technical use is the ratio of the mathematical expectation of the total time the object is in working order for a certain period of operation to the mathematical expectation of the total time the object is in working order and downtime due to maintenance and repair during the same period:

$$
K_{t u}=\frac{\overline{\mathrm{T}}_{f}}{\overline{\mathrm{T}}_{f}+\overline{\mathrm{T}}_{r}+\overline{\mathrm{T}}_{M}}
$$

where: $K_{t u}-$ coefficient of technical use;

$\overline{\mathrm{T}}_{M}$ - average maintenance time.

The coefficient of technical use seems to be more suitable for assessing downtime associated with the technical condition of the machines, since it takes into account scheduled maintenance [11-12]. However, if scheduled maintenance of combines is carried out during periods of time when harvesting cannot be performed (for example, due to 
increased humidity in the morning), it is preferable to use the availability factor.

Another reason for the decrease in the actual performance of the processes of combine harvesting of grain crops is the need to find the optimal values of the regulated parameters of the work of the combine harvesters. Non-optimal solutions for setting the combines can lead to long downtime of the equipment, an increase in grain losses and a decrease in its quality.

The quality of the processes of setting and technological adjustment of combine harvesters can be characterized by the following indicators:

- time of presetting;

- time of setting technological adjustments;

- optimality of the settings.

The optimality of the setting of the combine harvester is determined by the totality of the values of the parameters of the working devices, environmental conditions and the correlations between them. The optimality of the setting can be estimated by the level of losses, the quality of the threshed grain and threshing per unit time [13-15].

The time for setting and adjusting the technological configurations of the $\mathrm{CH}$ affects the actual performance of the harvesting process in the same way as the technical indicators mentioned above, reducing the available working time. The time spent on technological adjustment and setting of technological configurations of the combine harvesters leads to the decrease in shift productivity of the combines.

The need for operations for the technological adjustment of the combine harvesters is confirmed by the assessment of the third indicator highlighted in the group of the technological reasons for the decrease in the performance - the optimal setting of the combine harvesters. Non-optimal settings of the combine harvester lead to the increase in grain losses, to the decrease in the combine harvester productivity (work with incomplete loading), or to both of these consequences.

If the increase in grain losses does not affect the performance of the mechanized harvesting of grain crops (although, undoubtedly, significantly affects its effectiveness), then the decrease in productivity due to incomplete loading reduces the actual performance of the combine.

It is proposed to evaluate the influence of factors associated with the technological adjustment of the combine using two coefficients: the coefficient of technological adjustment (setting) $\left(K_{A}\right)$ and the load factor of the $\mathrm{CH}\left(K_{L}\right)$.

The coefficient of technological adjustment (setting) $\left(K_{A}\right)$ characterizes the time spent on setting up and adjusting the operating modes of the working devices of the $\mathrm{CH}$ :

$$
K_{L}=\frac{\overline{\mathrm{T}}_{\text {work }}}{\overline{\mathrm{T}}_{\text {work }}+\overline{\mathrm{T}}_{S}+\overline{\mathrm{T}}_{A}}
$$

where: $\overline{\mathrm{T}}_{\text {work }}$ - average time spent on useful work;

$\overline{\mathrm{T}}_{S}$ - the average time spent on setting up the combine;

$\overline{\mathrm{T}}_{A}$ - the average time spent on the adjustment of technological configurations.

The load factor $\left(K_{L}\right)$ shows how fully the claimed combine capacity is used:

$$
K_{L}=\frac{q_{a c t}}{q}
$$

where: $q$ - the claimed capacity of the combine harvester, $\mathrm{kg} / \mathrm{s}$;

$q_{a c t}$ - the actual capacity of the combine harvester, $\mathrm{kg} / \mathrm{s}$.

$$
q_{a c t}=\frac{S_{a} \times Y\left(1+K_{R}+K_{C}\right)}{t_{h}},
$$

where: $S_{a}$ - area (ha), actually harvested during continuous operation; $t_{h}$ (hours); 
$\mathrm{Y}$ - crop yield, tons/ha;

$\mathrm{K}_{R}$ - the ratio of straw and grain by weight (standard value of $1,5: 1$ );

$K_{C}$ - contamination of the crop stand by weight.

However, determining the load factor of the combine harvester using formulas (10), (11) under the real conditions of the combine harvesting of grain crops is very inconvenient, since the time $t_{h}$, used to calculate the $q_{a c t}$, is very difficult to define accurately. During operation, the combine performs turns and other maneuvers, during which the supply of grain mass stops, but there is no countdown. It is easy to take into account such breaks only in test conditions.

For a simpler assessment of the load factor of the combine $\left(K_{L}\right)$ it is possible to rely on the ratio of the speeds of the combine during the harvesting process. In the Russian standards for testing the combine harvesters, the concept of working speed is established, which corresponds to the estimated productivity:

$$
v_{e}=\frac{10 \times W_{e}}{L_{e} \times Y_{\text {prel }}}
$$

where: $W_{e}-$ is the estimated productivity of the combine, $\mathrm{t} / \mathrm{h}$ (can be calculated by the formula (3));

$Y_{\text {prel }}$ - preliminary crop yield excluding losses after the combine, tons/ha;

$L_{\mathrm{e}}-$ structural width of the reaper grab, $\mathrm{m}$

Preliminary yield is determined by manual harvesting and threshing of wheat from several random fields.

The load factor of the combine harvester can be calculated as the ratio of the actual harvesting speed to the speed corresponding to the design capacity $\left(v_{d}\right)$ :

$$
K l=\frac{v_{a c t}}{v_{d}},
$$

where: $v_{\text {act }}-$ the actual speed of the harvester during harvesting, $\mathrm{km} / \mathrm{h}$.

Such an approach to determining the load factor seems justified, since the speed of the combine is set as the result of the adjustment and is the value that is functionally related to both the number of losses and the performance of the combine.

The decrease in the time of use of combines and, accordingly, the shift productivity, is possible due to a number of organizational reasons: downtime due to the change of machine operators (including the inability to work around the clock); stops for refuelling; downtime due to waiting for machines for unloading grain; transportation, etc.

It is proposed to evaluate the organizational and logistic component of the reasons for the decrease in the performance of the $\mathrm{CH}$ using the coefficient of organizational downtime $\left(K_{O}\right)$ :

$$
K_{O}=\frac{\overline{\mathrm{T}}_{\text {work }}}{\overline{\mathrm{T}}_{\text {work }}+\overline{\mathrm{T}}_{\text {org }}}
$$

where: $\overline{\mathrm{T}}_{\text {work }}$ - average time to complete useful work; $\overline{\mathrm{T}}_{\text {org }}$ - average downtime for organizational reasons:

$$
\overline{\mathrm{T}}_{\text {org }}=t_{\text {oper }}+t_{\text {ref }}+t_{\text {log }}+t_{\text {trans }}
$$

where: $t_{\text {oper }}$ - is the average downtime associated with the operator (lunch break, shift, including the time of possible harvesting, but work is not carried out due to excess workload for the operator, etc.);

$t_{\text {ref }}$ - average downtime due to refuelling; 
$t_{l o g}$ - average downtime associated with waiting for machines for unloading grain;

$t_{\text {trans }}$ - average time of equipment transportation from field to field and to places of permanent location (brigades, field camps, machine parks, garages, etc.).

The actual performance of the processes of combine harvesting of grain crops can be described by the expression:

$$
\mathrm{P}_{a}=S_{a}=S_{W} \times K_{T U} \times K_{S} \times K_{O} \times K_{L},
$$

Evaluation of the performance of the process, in this case, can be calculated by the formula (2), as the ratio of $\mathrm{P}_{a}$ to $\mathrm{P}_{p}$.

\section{Results and discussion}

To increase the performance of the process of mechanized harvesting of grain crops, all the components presented in expression (16) should be considered. The choice of priority areas for improvement must be carried out based on the values of the coefficients $\mathrm{K}_{\mathrm{TU}}, \mathrm{K}_{\mathrm{S}}, \mathrm{K}_{\mathrm{O}}$, $\mathrm{K}_{\mathrm{L}}$ and the capabilities of planting enterprises.

In recent years, we have accumulated a significant amount of statistical data on the processes of combine harvesting of grain crops in planting enterprises of the Myasnikovsky District of the Rostov Region (Russian Federation), which together operate more than 60 machines of various manufacturers.

As a result of the analysis of indicators recorded at these farms in the period from 2014 to 2019, the following generalized data have been obtained (table 1):

Table 1. Average values of indicators of grain harvesting processes at the farms of the Myasnikovsky district of the Rostov region (Russian Federation) in 2014-2019.

\begin{tabular}{|c|l|c|}
\hline № & \multicolumn{1}{|c|}{ Indicator name } & $\begin{array}{c}\text { Average } \\
\text { value }\end{array}$ \\
\hline 1 & Duration of harvesting, days & 26 \\
\hline 2 & $\begin{array}{l}\text { Downtime due to weather conditions (rains, daily change in humidity, } \\
\text { etc.), } \mathrm{h}\end{array}$ & 10 \\
\hline 3 & Failure interval, $\mathrm{h}$ & 32 \\
\hline 4 & Recovery time, $\mathrm{h}$ & 5.5 \\
\hline 5 & Duration of maintenance per shift, $\mathrm{h}$ & 1.25 \\
\hline 6 & The main working time per shift (time to complete useful work), h & 6.5 \\
\hline 7 & Harvester setup time per shift, $\mathrm{h}$ & 0.5 \\
\hline 8 & The time to adjust the settings of the combine per shift, $\mathrm{h}$ & 0.6 \\
\hline & $\begin{array}{l}\text { Actual Download: } \\
\text { - at the production of the main product, tons/h: }\end{array}$ & 13.3 \\
\hline & - at operating speed, $\mathrm{km} / \mathrm{h}:$ & 4.8 \\
\hline 10 & $\begin{array}{l}\text { Estimated load: } \\
\text { - for the production of the main product, tons/h: }\end{array}$ & 17.4 \\
\hline 11 & - by operating speed, $\mathrm{km} / \mathrm{h}:$ & 6 \\
\hline 12 & Downtime due to logistics and organizational reasons, $\mathrm{h}$ & 4.3 \\
\hline 13 & The capacity of the combine harvester, $\mathrm{kg} / \mathrm{s}$ & 4 \\
\hline 14 & The ratio of straw and grain by weight $(\mathrm{Kr})$, & 11 \\
\hline 15 & Contamination of the grain mass (Kc), & 1.5 \\
\hline
\end{tabular}

Based on the data in table 1, the values of the coefficients given in formulas (4) - (16) are calculated (table 2). 
Table 2. The results of the calculation of the coefficients to determine the performance of the processes of combine harvesting of grain crops.

\begin{tabular}{|c|l|c|}
\hline № & \multicolumn{1}{|c|}{ Coefficient name } & Coefficient value \\
\hline 1 & Planned performance $\left(\mathrm{S}_{\mathrm{P}}\right)$, ha & 1413.18 \\
\hline 2 & Coefficient of weather conditions $\left(\mathrm{K}_{\mathrm{W}}\right)$ & 0.58 \\
\hline 3 & Coefficient of technical use $\left(\mathrm{K}_{\mathrm{TU}}\right)$ & 0.83 \\
\hline 4 & Coefficient of technological adjustment (setting) $\left(\mathrm{K}_{\mathrm{A}}\right)$ & 0.86 \\
\hline 5 & Load factor $\left(\mathrm{K}_{\mathrm{L}}\right)$ & 0.80 \\
\hline 6 & Coefficient of organizational downtime $\left(\mathrm{Ko}_{\mathrm{O}}\right)$ & 0.60 \\
\hline 7 & Actual performance $\left(\mathrm{S}_{\mathrm{A}}\right)$, ha & 480.57 \\
\hline
\end{tabular}

The value of the performance indicator of the processes of combine harvesting of grain crops can be determined by the formula (2). For the data given in tables 1, 2, the performance indicator is 0.34 .

The resulting assessment of the performance of the mechanized harvesting of grain crops indicates a very low degree of use of the potential of mechanization means. It is possible to judge the contribution of various reasons for the decrease in the harvesting performance by the value of the indicators presented in table 2 (Figure 2).

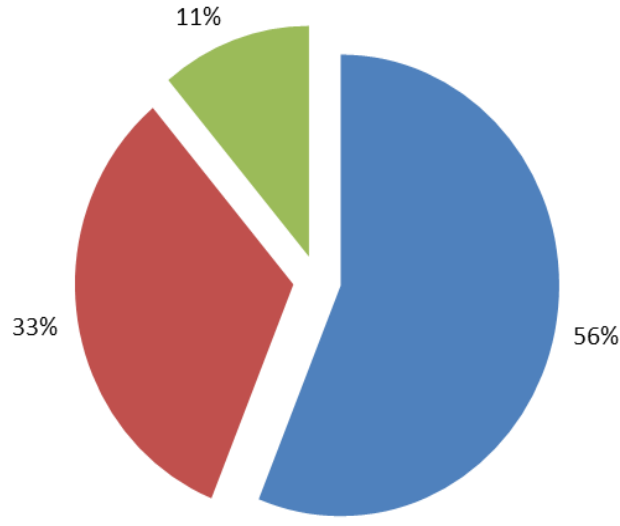

\author{
- Performance considering season \\ - Performance considering weather conditions \\ Actual performance
}

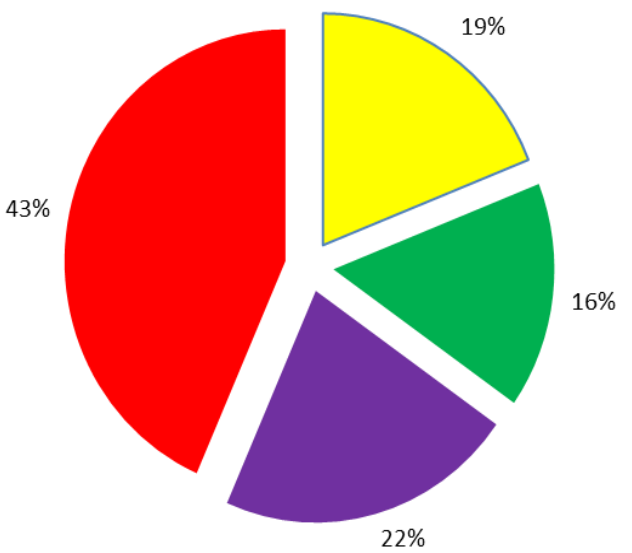

$\square$ Technical condition

W orking units configuration

- Incomplete load

- Organizational and logistical reasons

Fig. 2. Reasons for the decrease in the efficiency of the grain harvesting processes.

The analysis of the reasons for the decrease in the performance of the harvesting processes has shown that the most significant reason is weather conditions, organizational and logistical reasons. Weather conditions are uncontrollable, so there are practically no ways to reduce their impact. The reasons for downtime associated with logistics and the 
organization of work seem to be the most significant for the considered agricultural enterprises.

\section{Conclusions}

1. Presented in the paper approach to assessing the performance of the processes of the mechanized harvesting of grain crops allows not only to present the actual performance of the work, but also to determine the most promising ways of its increase.

2. The application of the presented methodology for assessing the performance of the processes of combine harvesting of grain crops requires the development of reliable procedures for the collection and management of documented information on various aspects of the agricultural company activities.

3. To develop a strategy of improving the harvesting processes, it is necessary to consider not only their performance, but also effectiveness, since the increase in performance may require unreasonably high expenses (for example, reducing downtime due to logistical reasons by involvement additional means of grain transportation will increase the below-cost per the kilogram of grain, with a slight increase in threshing).

\section{References}

1. V. Dimitrov, L. Borisova, I. Nurutdinova, V. Pakhomov, V. Maksimov, MATEC Web Conf. 226, 04023 (2018) DOI: 10.1051/matecconf/201822604023

2. L. Borisova, V. Dimitrov, Mordovia University Bulletin 27, 178-189 (2017) DOI: 10.15507/0236-2910.027.201702.178-189

3. A.K. Tugengol'd, V.P. Dimitrov, A.I. Izyumov, A.R. Yusupov, Russian Engineering Research 37, 440-446 (2017) DOI: 10.3103/S1068798X17050239

4. V. Bulgakov, V. Adamchuk, M. Arak, J. Olt, Agriculture and Agricultural Science Procedia 7, 35-39 (2015) DOI: 10.1016/j.aaspro.2015.12.027

5. S. Shepelev, V. Shepelev, Yu. Cherkasov, Procedia Engineering 129, 161-165 (2015) DOI: 10.1016/j.proeng.2015.12.026

6. E. Lorencowicz, J. Uziak, Agriculture and Agricultural Science Procedia 7, 152-157 (2015) DOI: 10.1016/j.aaspro.2015.12.010

7. W. Eduardo, B. Connie Tenin Su, T. Guilherme Pera, J. Vicente Caixeta Filho, Sustainable Production and Consumption 21, 228-238 (2020) DOI: 10.1016/j.spc.2019.09.002

8. T.U. Rehman, S. Mahmud, Y.K. Chang, J. Jin, J. Shin, Computers and Electronics in Agriculture 156, 585-605 (2019) DOI: 10.1016/j.compag.2018.12.006

9. A. Hafezalkotob, A. Hami-Dindar, N. Rabie, A. Hafezalkotob, Computers and Electronics in Agriculture 148, 207-216 (2018) DOI: 10.1016/j.compag.2018.03.012

10. M. Sujaritha, S. Annadurai, J. Satheeshkumar, S. Kowshik, L. Mahesha, Computers and Electronics in Agriculture 134, 160 (2017) DOI: 10.1016/j.compag.2017.01.008

11. I. Markvo, E. Zubrilina, V. Novikov, E3S Web of Conferences 126, 00054 (2019) DOI: $10.1051 / \mathrm{e} 3$ sconf/201912600054

12. E. Zubrilina, I. Markvo, V. Novikov, A. Beskopylny, L. Vysochkina, D. Rudoy, A. Butovchenko, IOP Conf. Ser.: Earth Environ. Sci. 403, 012063 (2019) DOI: $10.1088 / 1755-1315 / 403 / 1 / 012063$ 
13. D. Kortenbruck, H.W. Griepentrog, D.S. Paraforos, Computers and Electronics in Agriculture 140, 227-236 (2017) DOI: 10.1016/j.compag.2017.05.039

14. G. Craessaert, J. de Baerdemaeker, B. Missotten, O. Saeys, Biosystems Engineering 106, 103 (2010) DOI: 10.1016/j.biosystemseng.2009.12.012

15. A. Utamima, T. Reiners, A.H. Ansaripoor, Biosystems Engineering 184, 166-180 (2019) DOI: 10.1016/j.biosystemseng.2019.06.001 